Are Risk Preferences Stable?

Comparing an Experimental Measure with a Validated Survey-Based Measure

\author{
Lisa R. Anderson \\ College of William and Mary \\ Jennifer M. Mellor \\ College of William and Mary
}

College of William and Mary

Department of Economics

Working Paper Number 74

August 2008 
COLLEGE OF WILLIAM AND MARY

DEPARTMENT OF ECONOMICS

WORKING PAPER \#74

August 2008

\title{
Are Risk Preferences Stable? Comparing an Experimental Measure with a Validated Survey- Based Measure
}

\begin{abstract}
We examine the stability of risk preference within subjects by comparing measures obtained from two elicitation methods, an economics experiment with real monetary rewards and a survey with questions on hypothetical gambles. The survey questions have been validated by numerous empirical studies of investment, insurance demand, smoking and alcohol use, and recent studies have shown the experimental measure is associated with several real-world risky behaviors. For the majority of subjects, we find that risk preferences are not stable across elicitation methods. In interval regression models, subjects' risk preference classifications from survey questions on job-based gambles are not associated with risk preference estimates from the experiment. However, we find that risk classifications from inheritance-based gambles are significantly associated with the experimental measure. We identify some subjects for whom risk preference estimates are more strongly correlated across elicitation methods, suggesting that unobserved subject traits like comprehension or effort influence risk preference stability.
\end{abstract}

JEL Codes: C9, D8

Keywords: $\quad$ Risk Preferences, Laboratory Experiment, Survey

Lisa R. Anderson

Department of Economics

College of William and Mary

Williamsburg, VA 23187-8795

lisa.anderson@wm.edu
Jennifer M. Mellor

Department of Economics

College of William and Mary

Williamsburg, VA 23187-8795

jmmell@wm.edu 
Do individuals respond to risk in a consistent manner? A growing literature has explored whether individual-level risk preference varies with incentives (e.g., Camerer and Hogarth 1999), implementation mode (e.g., von Gaudecker et al. 2008), or over time (e.g., Andersen et al. 2008). Several recent studies have also examined whether risk preference appears stable across different institutions or laboratory designs (e.g., Isaac and James 2000; Berg et al. 2005). These studies raise intriguing questions for economic theories of choice under uncertainty, which typically assume that risk preference is an exogenous trait. In addition, evidence that risk preference varies within subjects raises challenges for policy decisions that hinge on assumptions about the public's degree of risk tolerance, as noted by Berg et al. (2005).

The present study examines the consistency of risk preference measures using a withinsubjects design. We compare a risk preference measure derived from an economics experiment with real monetary payoffs to risk preference measures obtained from survey questions about hypothetical gambles. Similar survey questions have been included on several large U.S. household surveys, and risk preference measures constructed from them have been found to be significantly associated with behaviors such as financial investment, insurance demand, risky health behaviors, education, marriage, and fertility (e.g., Barsky et al. 1997; Dave and Saffer 2007; Schmidt 2008). Thus, the hypothetical gamble questions used here have been validated to a greater extent than some experimental measures. In addition, the experiment-based measure we employ has been shown to be associated with real-world risky behaviors in several recent studies (e.g., Elston et al. 2005; Lusk and Coble 2005; Anderson and Mellor forthcoming).

In our experiment, more than 200 subjects participated in a version of the Holt and Laury (2002) lottery choice task where each made 10 choices between two lotteries and each lottery 
paid one of two amounts. The amounts were such that one lottery was associated with less risk than the other, and the point at which subjects switched from the safe lottery to the risky one can be used to define their range of risk aversion. Subjects then completed a survey which included questions on hypothetical risky situations similar to those used in several large household surveys. Responses to these questions can be used to construct both ordinal and cardinal measures of risk aversion.

We first use the combined data to model subjects' risk preference defined from the experiment as a function of their risk preference indicated by their choices between a job with certain income and a job with risky income. For the majority of subjects in our sample, the survey-based risk preference classifications are not significantly associated with risk aversion defined from the experiment. Further, there is no evidence of a monotonic relationship between the level of risk aversion implied by job-based survey responses and the size of a risk aversion parameter elicited from the experiment.

We then examine subject responses to a second series of hypothetical gamble questions included on the survey. These questions incorporate the same degree of risk as the first set of questions, but ask the respondents to choose between inheriting a certain level of wealth or a risky level of wealth. We use these survey questions to examine whether subjects respond in a similar manner across the two sets of hypothetical questions, and whether responses to one set of questions are more closely related to behavior in the lottery choice task than the other. We find that most subjects' risk classifications vary across the two series of questions, and that the classifications based on inheritance gambles are more closely related with the experimentalbased measure than the job gamble classifications. Finally, we use responses from both sets of 
hypothetical questions to identify subjects for whom risk preference exhibits more stability. An important finding from this study is that among subjects who make no logical inconsistencies in any of their survey responses, risk preference estimates obtained from the survey responses are more strongly associated with risk preference estimates from the lottery choice task. This suggests that unobserved subject effort or ability may partially explain previously reported findings of risk preference instability.

The remainder of this paper is organized as follows. Section 1 provides a review of prior studies on risk preference stability across institutions, and Section 2 describes the two risk preference elicitation methods used in our study. In Section 3, we describe our experimental procedures and the analysis sample. Section 4 presents results from interval regression models of risk aversion in the experiment using the survey-based measures of risk aversion as explanatory variables, and Section 5 concludes.

\section{Previous Studies of Risk Preference Stability}

Several prior studies have reported that individual risk preference is not stable across institutions or designs of a laboratory experiment. In this section we focus on studies that have employed a within-subjects design, that is, where risk preference for the same subject was elicited using more than one method. Three of these studies conducted laboratory experiments using the Becker-DeGroot-Marschak (hereafter BDM, 1964) procedure, in which subjects are asked to state a selling price (i.e., certainty equivalent) for a lottery they are endowed with at the outset of the experiment. If the selling price exceeds a random number drawn by the experimenter, the subject plays the lottery and is awarded its proceeds; if the random number exceeds or equals the stated selling price, the subject receives an amount equal to the random 
number and does not play the lottery. Given the parameters of the experiment and the stated selling prices, values of a risk preference parameter can be estimated for each subject from multiple rounds of the experiment. It is possible to observe values of this parameter consistent with risk seeking, risk aversion, and risk neutrality.

In Isaac and James (2000), subjects participated in both the BDM procedure and a firstprice auction. ${ }^{1}$ Estimates of individual subjects' constant relative risk aversion (CRRA) utility function parameter varied significantly across the institutions. The majority of the subjects had values consistent with risk aversion in the first-price auction, but only three of those subjects were also risk averse according to the BDM procedure. Moreover, the numerical rankings of the subjects' risk aversion parameters were not consistent across the institutions, and the Spearman rank correlation coefficient of the parameters was negative and statistically significant. Berg et al. (2005) built on this analysis by comparing subjects' behavior using less restrictive assumptions about the form of the utility function, increasing the number of gambles in the BDM procedure, and adding a third institution, an English clock auction. As in Isaac and James (2000), subjects' behavior varied across the institutions, with 28 of 48 subjects exhibiting different risk preferences (e.g., risk seeking in one setting but risk averse in another) across the BDM procedure and the first-price auctions, and 38 of 48 behaving differently across the English and first-price auctions. To test whether the rank order of subjects' risk coefficients was consistent across the institutions, regressions of the risk parameters on one another were estimated, but no statistically significant regression coefficients were observed.

1 A risk preference parameter was inferred from behavior in the first-price auction using the bid function proposed by Cox et al. (1982). 
A related study by James (2007) compared estimates of risk aversion parameters obtained from administering the BDM procedure at different points in time. Subjects played either the selling version of the BDM procedure (described above) or a buying version (in which they were asked to state an offer price on a lottery). Subjects' estimated risk preferences were found to shift from risk seeking to risk neutrality between an early baseline and a late baseline in the selling version of BDM, but were more stable over time in the buying version of BDM.

In the present study, we define a subject's risk preference from decisions in the lottery choice experiment. A few studies have examined within-subject stability of risk preferences between this task and another exercise. In Dave et al. (2007), subjects played both the Holt and Laury (2002) task and the Eckel and Grossman (2002) task; the latter is simpler in that subjects make only one decision as opposed to ten. Risk aversion parameters obtained from both experiments were pooled and the data were used to run a regression of risk aversion on several variables. An indicator variable for the Holt and Laury exercise had a positive and significant coefficient, suggesting that subjects exhibited greater risk aversion in that task than the Eckel and Grossman task. While there were significant differences in the size of risk aversion parameters across tasks, the correlation between the two risk preference parameters was not reported.

Deck et al. (2008) compared behavior in the lottery choice task to the same subjects' behavior in a variation of the game show "Deal or No Deal." In that task, each subject was presented with 12 "briefcases" containing cash payoffs ranging from $\$ 0.01$ to $\$ 100$. Before selecting any cases the subject was given the choice of accepting $\$ 2.99$ or selecting a case. If the subject turned down the offer and selected a case, she was presented with a new offer that was a specific percentage of the average amount of money in the remaining cases. The task continued 
until the subject either accepted an offer or only two cases remained, at which point the subject selected one to eliminate and received the contents of the remaining case. Observations of accepted and rejected offers were used to construct a range of parameter values of risk aversion, which were then compared to the range obtained from the Holt and Laury exercise. The midpoints of these two ranges had a correlation coefficient of only 0.008 , with a $p$-value of 0.94 .

We contribute to this small literature by examining the consistency of risk preferences within subjects and across two elicitation mechanisms. An important feature of our work is that we use two mechanisms that have been shown to produce risk preference parameters correlated with various real-life risk behaviors in previous studies. Further, we compare behavior in the lottery choice experiment to responses from two series of hypothetical questions that present the same degree of risk in different contexts. One context allows subjects to gamble with their lifetime income, while the other gives subjects the choice to gamble with inherited wealth. In addition, we use our data to distinguish subjects who are internally consistent in all survey responses, and test whether this distinction can identify subjects for whom risk preferences are more stable across elicitation methods. Our analysis uses a larger sample of paid participants compared to most prior studies on risk preference stability. ${ }^{2}$

Our work is similar to a few studies that compare decisions in experimental risk-taking tasks to responses from survey questions that elicit risk preference. Kruse and Thompson (2003) compared subjects' willingness to pay for a lock that cut the chance of burglary in half with choices in a laboratory experiment based on identical losses and probabilities, but with real money at stake. The experimental and survey-based measures were consistent on average, but on

${ }^{2}$ Of the studies cited above, only the sample used by Dave et al. (2007) is larger, at 881 subjects. 
an individual level they were consistent for less than one-quarter of the subjects. Dohmen et al. (2005) used data on 450 subjects who participated in an economics experiment with real payoffs, and also completed a survey with questions on self-reported willingness to accept risks. ${ }^{3}$

Willingness to accept risk was a significant predictor of risk-taking behavior in the lab, even after controlling for a number of demographic characteristics of participants.

Finally, the Deck et al. (2008) study cited above also administered a survey with different risk preference questions after subjects completed the lottery choice task and the Deal or No Deal game. With one exception, none of the pairwise correlation coefficients between the experimentand survey-based risk preference measures was statistically significant. The notable exception was a significant positive correlation between a risk aversion measure obtained from the lottery choice experiment and a 4-category scale of risk aversion defined from questions on job gambles similar to those we use. While our study is similar in the comparison of these two elicitation methods, several differences exist. We use a larger subject pool (236 subjects compared to 75) and the payoffs in our experiment are three times larger. We examine two series of survey questions on hypothetical gambles, define both 6-category ordinal measures and cardinal measures from the responses, and estimate interval regression models. The next section describes the elicitation methods in more detail.

\section{Risk Preference Elicitation}

\subsection{Measuring Risk Preference with a Lottery Choice Task}

In the Holt and Laury (2002) design, subjects make 10 choices between either Option A

${ }^{3}$ Potential payoffs were high relative to standard research experiments, but subjects were told that there was a 1 in 7 chance that they would be paid for their participation. If an individual was chosen to be paid for the lottery choice task, they were later mailed a check for their earnings. 
or Option B, where each option is a lottery that pays one of two amounts. In each decision, Option A is the "safe" choice and Option B is "risky," since Option A has less variability in the payoffs than Option B. The 10 decisions differ in terms of the probability of winning the higher prize in each lottery. In Decision 1, the higher prize is paid if the throw of a 10 -sided die is 1 and the lower prize is paid for any other throw of the die. For Decision 2, the higher prize is paid if the result of the die throw is 1 or 2 and the lower prize is paid if the die was 3 through 10 . By Decision 9 there is a $90 \%$ chance of winning the higher prize, and Decision 10 is a choice between a certain amount in Option A and a certain amount in Option B.

Table 1 shows the lottery choices for all 10 decisions in our version of the experiment, in which payoffs were three times those used in the Holt and Laury baseline treatment. In Decisions 1 through 4, the expected payoff for Option A is higher than the expected payoff for Option B; in Decisions 5 through 10, Option B has a higher expected payoff. Subjects generally begin by choosing Option A (the safe option) in Decision 1, when the chance of winning the higher Option B payoff is relatively small. The point at which subjects switch from the safe option to the risky option can be used to classify their risk aversion level. For example, subjects who choose Option A (the safe choice) in the first four decision rows are risk neutral. A risk averse subject will choose Option A more than four times and a risk-seeking subject will choose the safe option fewer than four times.

Decisions in the experiment can also be used to define a range of values for a risk aversion parameter. These ranges are reported in Table 2 for a utility function of constant relative risk aversion: 
(1) $U(Y)=\frac{Y^{1-r}}{1-r}$

where $r$ is the coefficient of relative risk aversion and $Y$ is the payoff in the lottery. For example, suppose an individual chooses the safe option in the first three decisions, then chooses the risky option for each subsequent decision. The lower bound of the risk aversion parameter is determined by solving for $r$ such that the individual is indifferent between Option A and Option B at Decision 3:

(2) $0.3 \frac{6}{1-r}^{1-\gamma}+0.7 \frac{4.80^{1-\gamma}}{1-r}=0.3 \frac{11.55^{1-r}}{1-r}+0.7 \frac{0.30^{1-r}}{1-r} \Leftrightarrow r \equiv-0.49$

Likewise, the upper bound is $r$ such that the individual is indifferent between Option A and Option B at Decision 4:

(3) $0.4 \frac{6}{1-r}^{1-\gamma}+0.6 \frac{4.80^{1-\gamma}}{1-r}=0.4 \frac{11.55^{1-\gamma}}{1-r}+0.6 \frac{0.30^{1-r}}{1-r} \Leftrightarrow r \equiv-0.15$

Values of $r<0$ indicate risk-seeking preferences, $r=0$ indicates risk neutrality, and values of $r>0$ indicate risk aversion.

The basic Holt and Laury (2002) design has been used in many subsequent studies on risk attitudes, including several that establish a link between decisions in the experiment and realworld risky behaviors. For example, Elston et al.(2005) conducted the experiment at two small business conventions and reported that full-time entrepreneurs were significantly more risk tolerant than part-time entrepreneurs and non-entrepreneurs. Lusk and Coble (2005) compared 
subject responses to survey questions on the willingness to consume genetically-modified foods to subject decisions in a lottery choice experiment and found that the experimental measure was significantly associated with risk-taking behavior. Anderson and Mellor (forthcoming) reported that subjects with higher values of risk aversion were less likely to smoke and more likely to wear seat belts.

\subsection{Measuring Risk Preference with Hypothetical Gambles}

Our second means of measuring subject-specific risk preference is through survey questions involving hypothetical gambles. Variations of these questions appear in several large panel surveys of U.S. households: the Health and Retirement Study (HRS), the Panel Study of Income Dynamics (PSID), and the National Longitudinal Survey of Youth 1979 (NLSY79). Given their widespread availability, these questions have been used to define and control for risk preference in studies of a wide range of behaviors, from financial investment to fertility.

Barsky et al. (1997) analyzed the hypothetical gamble questions as they originally appeared in the 1992 wave of the HRS. In that year, the first question in the series began: "Suppose you are the only income earner in the family, and you have a good job guaranteed to give you your current (family) income every year for life. You are given the opportunity to take a new and equally good job, with a 50-50 chance it will double your (family) income and a 50-50 chance it will cut your (family) income by a third. Would you take the new job?.” Respondents who turned down the new job were asked a follow-up about taking the new job if the chances were 50-50 that income would double, and 50-50 that income would be reduced by one-fifth. Respondents who accepted the new job in the first scenario were asked a follow-up in which the circumstances became more risky; specifically the question referred to a 50-50 chance that 
income would double, and a 50-50 chance that income would fall by one-half. Based on replies to the two questions they were posed, respondents were classified into one of four categories ranging from least risk tolerant (rejecting the new job in both cases) to most risk tolerant (accepting the new job in both cases).

The original study by Barsky et al. (1997) used a parameter measure of risk tolerance defined from these questions as an explanatory variable in a series of regression models of individual behaviors. While risk tolerance explained a relatively small portion of the variation in these behaviors, its estimated effects were statistically significant and of the expected sign in most cases. Respondents who were more risk tolerant according to the survey questions were more likely to report ever having smoked and smoking at the time of the survey; they also were more likely to drink, and reported drinking a higher number of drinks per day. More risk tolerant respondents were significantly more likely to be self-employed, not own health insurance, and not own life insurance. As risk tolerance increased, the share of the investment portfolio allocated to stocks also increased among respondents.

Several subsequent studies of wealth and investment decisions have used the hypothetical gamble responses to control for individual risk preference. Using the HRS, Lusardi (1998) found that a categorical measure of risk aversion was significantly associated with wealth accumulation, and Rosen and $\mathrm{Wu}(2004)$ reported that a risk-taking indicator was associated with risky asset ownership. Using the PSID, Charles and Hurst (2003) found a strong correlation between parental risk tolerance and child risk tolerance indicator variables, and showed that adult children with higher levels of risk tolerance were more likely to own a business and more likely to own stocks than those with the lowest levels of risk tolerance. 
Several recent studies on non-financial decisions also validate the use of hypothetical gamble questions to define risk preference. Kan (2003) used PSID data and found that risk aversion was negatively and significantly associated with job changes and residential moves. Also using PSID data, Brown and Taylor (2007) showed that risk aversion was negatively associated with educational attainment, and Schmidt (2008) reported that high levels of risk tolerance were associated with delayed marriage, earlier births at young ages, and delayed fertility at older ages among highly-educated women. Spivey (2007) used data from the NLSY79 to demonstrate that risk aversion was significantly associated with the timing of first marriage. The evidence regarding the predictive power of the survey-based measure is mixed in studies related to health and healthcare. Using a categorical measure of risk aversion as a control variable, Lahiri and Song (2000) reported a negative and significant effect on smoking initiation, and Dave and Saffer (2007) reported a negative and significant effect on alcohol consumption. In contrast, Sloan and Norton (1997) reported insignificant effects of risk aversion indicators on long-term care insurance demand, and Picone et al. (2004) found that risk tolerance had either statistically insignificant effects or significant and wrong-signed effects on the demand for preventive medical tests.

\subsection{Similarities and Differences in Risk Preference Elicitation Methods}

As described above, both elicitation methods used in this study produce measures of risk preference that have been validated by several studies documenting their association with "real world" risky behaviors. Both tasks share some additional features. One is that they are relatively simple pairwise choices and can be administered with minimal instruction to subjects. For this reason, pairwise choice experiments may be less prone to misinterpretation and strategic 
behavior than certainty equivalent measures. Further, in an experimental comparison of risk elicitation methods, Hey et al. (2007) found that pairwise choice methods were associated with both less noise and less bias than certainty equivalent measures, including the BDM procedure. Another similarity is that both mechanisms have been studied in the context of temporal stability, and there is evidence that subjects tend to respond to each in a stable manner over time. Sahm (2007) used panel data from the HRS to show that risk tolerance defined from the gamble questions is relatively stable for individuals over time, and Andersen et al. (2008) showed that risk attitudes defined from the lottery choice task are stable over time. Finally, both tasks allow the identification of subjects who did not take the task seriously. The selection of the safe lottery in the $10^{\text {th }}$ decision (favoring $\$ 6$ to $\$ 11.55$ ) can be used to identify subjects who misunderstood the task or took it less seriously, and logical inconsistencies within the full set of survey question responses can identify subjects who were not reading or responding thoughtfully. These procedures are described in more detail in the next section.

However, there are some obvious differences in the two tasks, such as the hypothetical nature of the gambles and the large difference in the scale of the payoffs. Holt and Laury (2002) found that increasing the size of real payoffs leads subjects to behave in a more risk averse manner; however, there were no significant differences in subject decisions across one treatment with low real payoffs and several treatments with high hypothetical payoffs. Further, while differences in the scale of the payoffs may lead subjects to be more risk averse, there is little reason to think that payoff differences would cause the rank order of risk aversion estimates to change across the two tasks. Nonetheless, these differences may reduce our chances of finding consistency across the risk preference measures obtained from both tasks. 


\section{Experimental Design}

We conducted 24 experimental sessions with roughly 10 subjects per session. Subjects were recruited from introductory-level undergraduate courses at the College of William and Mary. Subjects first completed an Internet-based version of the lottery choice questionnaire designed by Holt and Laury (2002). ${ }^{4}$ Appendix 1 contains the instructions read and provided to subjects. Once all 10 lottery choices were made, one decision was randomly chosen for payment, and a die toss was used to determine the result of the chosen lottery. Subject earnings in the experiment averaged $\$ 7.08$, and including the show-up payment subjects received, overall earnings were $\$ 14.58$ on average. After earnings were determined but before they were paid, subjects completed a survey with the hypothetical gamble questions. A total of 239 subjects participated in the experimental sessions; one subject did not complete the survey and two other subjects who chose the safe option for Decision 10 were dropped from the sample. Because a safe choice for the tenth decision means favoring a certain $\$ 6$ over a certain $\$ 11.55$, this was viewed as a sign that the subject did not understand the instructions. ${ }^{5}$

In Holt and Laury (2002), the lottery choice experiment was conducted with 212 subjects who were a mix of undergraduate students, MBA students, and business school faculty. Twentysix percent of the subjects were risk neutral, $8 \%$ were risk seeking, and $66 \%$ were risk averse. As shown in Table 2, the classification of our study subjects is more risk averse on average.

${ }^{4}$ The experiment was conducted using the Veconlab website designed by Charles Holt: http://veconlab.econ.virginia.edu/admin.htm.

5 Similarly, Harrison et al. (2007) excluded 14 subjects whose choices suggested they were confused or unmotivated. 
Twenty-one percent are risk neutral, $4.7 \%$ are risk seeking, and nearly $75 \%$ are risk averse. Recall that it is typical for subjects to begin with a safe choice in the first decision row and to switch to the risky choice in a subsequent row. In our experiment and in others, some subjects "switched back" to the safe option after having chosen the risky option. In Holt and Laury (2002), 13\% of 212 subjects switched back to the safe option in an initial low-payoff treatment, and $7 \%$ switched back in a second low-payoff treatment. In our experiment, only 6 of 236 subjects (2.5\%) did so. Like Holt and Laury (2002), we found that most (67\%) subjects who switched back did so only once. The comparable percentage in their sample is around $75 \%$.

In our empirical analysis of the lottery choice experiment, we use each subject's range of risk aversion defined by their switch from the safe lottery to the risky lottery, and reported in Table 2. For the small number of subjects who made multiple switches between the safe and risky option, we follow Harrison et al. (2007) in determining the range of values for relative risk aversion. The lower bound of the range is determined by the first switch a subject made from the safe lottery to the risky lottery. For example, if a subject chose Lottery A for the first four decisions then switched to Lottery B for the fifth decision, we use the lower bound associated with four safe choices, which is -0.15 (from Table 2). The upper bound is determined by the last safe choice a subject makes. Continuing with the example above, if this subject switched back to Lottery A for the sixth decision and then chose Lottery B for all remaining decisions, we use the upper bound of the range of relative risk aversion associated with six safe choices, which is 0.68 (from Table 2).

At the end of the session, all subjects completed a survey that contained questions on demographic traits and parental income as well as several questions concerning hypothetical 
gambles similar to those used in the later waves of the HRS. The first set of questions began:

"Suppose that you are the only income earner in your family. Your doctor recommends that you move because of allergies and you have to choose between two possible jobs. The first would guarantee you an annual income for life that is equal to your parents' current total family income. The second is possibly better paying, but the income is less certain. There is a 50-50 chance the second job would double your total lifetime income and a 50-50 chance that it would cut it by a third. Which job would you take - the first job, or the second job?"

This wording is similar to the revised 1998 HRS question in that it avoids status quo bias by presenting subjects with a choice between two new jobs, as opposed to the original 1992 question which offered a choice between one's current job and a new job. The above wording also reflects a change we introduced because the questions were posed to students: the reference income in our questions is the current income of the respondents' parents.

After this question, all subjects were asked four additional questions. Two presented more risky options, in which the downside risk associated with the second job was increased to a $50 \%$ cut in income, and then a $75 \%$ cut in income. Two other questions presented less risky options than the initial scenario, where the downside risk of the second job was a $20 \%$ cut in income or a 10\% cut in income. All five questions are reprinted in Appendix 2. In the HRS, respondents who chose the "safe" job were asked only the subsequent questions with lower downside risk, and respondents who chose the "risky" job were asked only subsequent questions with higher downside risk.

Because subjects in our survey answered all five questions, we can examine how well respondents understood the questions or how seriously they took them. We identified "inconsistent" responders as subjects who chose the second (risky) job for one possible income loss, then reverted to the first (safe) job when possible loss was reduced. Likewise, we identified 
an inconsistent subject as one who chose the first (safe) job for a given income loss, then chose the second (risky) job when the possible loss was increased. Of the 236 subjects in our analysis sample, 21 gave a "don't know" response to at least one of the job gamble questions, and 17 others gave inconsistent responses.

In addition to these five questions, the survey included a second series of hypothetical gamble questions. These questions were identical in terms of the probabilities and percentage wins and losses, but the context was different. Instead of referring to a job with risky earnings, the initial question began:

"Suppose that a distant relative left you a share in a private business worth one million dollars. You are immediately faced with a choice -- whether to cash out now and take the one million dollars, or to wait until the company goes public in one month, which would give you a 50-50 chance of doubling your money to two million dollars and a 50-50 chance of losing one-third of it, leaving you 667 thousand dollars. Would you cash out immediately or wait until after the company goes public?"

As in the first series, this question was followed by four additional questions that all subjects were asked (see Appendix 2), and six possible response categories can be defined. ${ }^{6}$

Prior analysis of multiple waves of HRS data has found that subject responses to the same hypothetical questions over time have a high level of consistency (Sahm 2007). In light of that, we might expect risk preferences to be stable across the two sets of hypothetical questions since they presented the same probabilities and percentage gains and losses. However, there is some evidence that individual responses to attitudinal questions on risk-taking vary with the context. Dohmen et al. (2005) found that risk tolerance variables defined by questions on self-reported willingness to take risks in one's career, in sports, in car driving, etc., had significant correlations

${ }^{6}$ This question was included in the 2002 HRS. We are not aware of any studies that analyze responses to this question. 
averaging 0.52 . In contrast, Weber et al. (2002) found that context-specific measures of risk attitudes (e.g., measures of "financial risk," "social risk" etc., defined from factor analyses) had correlations ranging from 0.14 to 0.52 , with an average of only 0.32 , and Deck et al. (2008) reported even smaller correlation coefficients between domain-specific risk-taking attitudes. Thus, we included this second series of questions to examine whether subjects' exhibit stability in their risk preference estimates across the different contexts, or whether context affected responses to the question. Additionally, we included both sets of hypothetical questions to refine our examination of risk preference stability across the survey questions and the lottery choice task. We conjecture that subject lottery choices in the experiment may be more similar to responses to the inheritance gamble questions because both lottery winnings and inheritances are windfall gains or additions to discretionary income, as opposed to income from earnings which may be viewed as essential. That said, other differences in the context may have made one question appear more hypothetical than the other, creating another source of difference with the real-stakes lottery choices.

\section{Results}

We use combined data from the experiments and the survey question responses to examine the main research question from this study: Do individual measures of risk preference appear stable across the lottery choice exercise and the hypothetical gambles? In doing so, we also test for stability across the series of hypothetical gamble questions, and compare the experimental measure of risk preference with each set of risk aversion classifications from the gambles.

Table 3 reports the categories of risk aversion defined from both series of gamble 
questions, and the distribution of subjects across classifications. We employ the same 6 classifications defined by researchers using the HRS questions. The classifications range from least risk averse (accepting the risky job when the downside risk is a loss of $33 \%, 50 \%$ and $75 \%$ of income), to most risk averse (rejecting the risky job when the downside risk is a loss of $33 \%$, $20 \%$ and $10 \%$ ). We also report the share of subjects who responded to any of the five questions in the series with "don't know," as well as subjects who responded to each series in an inconsistent manner, as described in the previous section.

Table 3 shows that there is a large difference in the number of inconsistent responses across the two series: while only 17 of the 236 subjects responded in an inconsistent manner to the first series, $105(45 \%)$ did so in the second series. This difference is surprisingly large, and suggests that many subjects did not take the second series of questions as seriously as the first. The second series of gamble questions followed immediately after the first series on the survey and subjects may have become tired or bored from answering the relatively long questions. Context differences may have contributed as well, but because all surveys used the same ordering of the questions, we are unable to formally test whether the differences are driven by context or order.

Table 3 also reports differences in the degree of risk aversion among the subjects who responded in a logical manner to each set of questions. Of 198 subjects who could be consistently classified using their job gamble responses, $13 \%$ fell into the bottom-two risk aversion categories. However, $39 \%$ of subjects fell into these categories using the inheritance gamble questions. Thus, the second series elicited a lower degree of risk aversion. Table 4 reports a two-way tabulation of subjects' risk aversion classifications based on the 97 subjects 
who responded to both questions consistently. If subjects responded in the same way to both series, the bolded cells on the diagonal would account for all observations; as it stands, they represent only 33 of 97 respondents, or $34 \%$. If we count those cells falling within one classification higher or lower in each series, 59 of 97 subjects or 61\% “overlap" categories. When we use responses to construct two categorical measures of risk preference ranging from 1 to 6 , we find that the Spearman rank correlation coefficient is positive and significant, but small at $0.175(p=0.09 ; \mathrm{n}=97)$. This suggests that subjects' responses across the two series of questions are weakly correlated at best, which is consistent with previous findings on measures of domainspecific risk attitudes.

We next examine the correspondence between subject responses to the hypothetical gamble questions and their decisions in the lottery choice experiment. Given the number of subjects who responded in an illogical or inconsistent manner to the second series, we start by using the job series of questions. This empirical analysis consists of interval regression models of the range of risk aversion defined from the lottery choice task. Interval regression allows us to specify the dependent variable as a range defined by the subject's lower and upper bounds of the risk preference parameter, and to account for cases where the data are right- or left-censored (e.g., the range is bounded by infinity). The explanatory variables in these models include indicators for the different risk aversion classifications, with the omitted category being the two least risk averse classifications (which were combined due the small number of subjects in the first category). If the ordering of risk preferences is stable across the experiment and the job gamble series, we should see that all four coefficients have positive signs, and that the magnitude of the coefficients increases monotonically across categories $3,4,5$, and 6 . 
Results are shown in Table 5; in column (1) “don’t know” responses were excluded and in column (2) "don't know" responses were included. ${ }^{7}$ All specifications also control for subject sex, race, academic classification, and household income. ${ }^{8}$ As shown in the first two columns, only two of the four coefficients for the risk aversion indicator variables have the expected positive sign. Relative to the least risk averse, those in categories 3 and 4 made decisions in the lottery choice game that were associated with a lower range of risk aversion (but not significantly so). Neither of the two positive coefficients is significant, and the coefficient for response category 6 is smaller in magnitude than the coefficient on category 5 . We tested the joint significance of the coefficients on the four response classifications, and cannot reject the null hypothesis that they are jointly equal to zero ( $p$-values range from 0.17 to 0.19 ). These results suggest that risk preferences estimates are not stable across the two elicitation methods.

Columns (3) and (4) of Table 5 report results of interval regression models using the risk preference classification based on the second series of hypothetical gamble questions. These results are somewhat more supportive of a correlation between risk preference as measured by

${ }^{7}$ We included an indicator variable for "don't know" responses, and re-coded the risk aversion category dummies from missing to zero for these cases. We also examined a sample that included the full 236 subjects, in this case also including an indicator for the inconsistent responses and re-coding the risk aversion dummies from missing to zero. Results were not substantively different and the indicator for inconsistent responses had an insignificant negative coefficient.

${ }^{8}$ Of the 236 subjects, $48 \%$ were female, $15 \%$ were nonwhite, $42 \%$ were freshmen, $21 \%$ sophomores, and $18 \%$ each were juniors and seniors. Students were asked to report their parents' annual household income in seven possible categories. The three lowest categories (under $\$ 60,000)$ were combined as the omitted category in the regressions reported in Table 4 , and $18 \%$ of students had parental income between $\$ 60,000$ and $\$ 80,000,19 \%$ had parental income between $\$ 80,001$ and $\$ 100,000,28 \%$ reported parental income between $\$ 100,001$ and $\$ 150,000$, and $21 \%$ reported income greater than $\$ 150,000$. 
the two elicitation methods. The coefficients on the risk aversion indicators are all positive and they are jointly significant with $p$-values of 0.03 and 0.05 . However, only one coefficient is individually significant, and the magnitudes of the coefficients are not strictly increasing in size across categories 3 through 6 .

Thus far, results suggest that subject's risk preference classifications vary across the different sets of survey questions, and that risk preferences elicited from hypothetical inheritance gambles are more closely related to choices in the lottery experiment than risk preferences elicited from hypothetical job gambles. We next use our data to address several other questions. The first question is whether a cardinal measure defined from the hypothetical gamble questions is more closely related to the experiment-based risk preference measure than are ordinal classifications. Kimball et al. (forthcoming) note that in contrast to ordinal rankings, a cardinal measure quantifies the difference in risk aversion across the categories. The second question we investigate is why risk preference defined from the inheritance gamble responses exhibits a stronger association with the experimental measure.

The results using the cardinal proxies of risk aversion as explanatory variables are shown in Table 6. We use the parameter values for risk aversion reported by Kimball et al. for researchers using the HRS-type gamble questions in datasets other than the HRS. ${ }^{9}$ These cardinal values are assigned to respondents based on their risk aversion classifications from the survey questions. The proxies constructed from either the job series or the inheritance series have positive coefficients in columns (1) and (2), but neither effect is significant. However,

\footnotetext{
9 These are available at (http://www.umich.edu/ shapiro/data/risk preference). We use the proxy values defined for status-quo bias free questions.
} 
consistent with the Table 5 results, the magnitude of the risk aversion coefficient is larger and the standard error is smaller when the inheritance series proxy is used.

One explanation for this difference is that the context in the inheritance-gamble questions is more closely related to lottery choices in the experiment. For example, subjects may view both the inheritance and the earnings from the experiment as windfall gains. Additionally, it might be that the sample of those who responded consistently to the inheritance series of questions has more stable risk preferences. In this case, differences in the sample, as opposed to the variable, may explain our results. In columns (3) and (4) we investigate this further by limiting the sample to the 97 respondents who report consistent answers to both series of gamble questions. The results are intriguing: both coefficients on the risk aversion parameters increase in magnitude, and the coefficient on risk aversion as measured by the inheritance gamble series becomes significant. The latter is evidence of stability in risk preferences across the two methods, although the size of the coefficient is too low for there to be a 1-1 correspondence. The fact that both coefficients increase suggests that restrictions on the sample contribute to the finding of risk preference stability. For some subjects in our study - those who were "consistently consistent" the rank ordering of risk aversion parameters is significantly associated across both the lottery choice tasks and the hypothetical gamble questions. This evidence contrasts with Berg et al. (2005) who found no statistically significant coefficients when risk preference parameters were regressed on one another.

We also examined how changes in the sample affected Spearman rank correlation coefficients for each of the 6-category risk aversion measures defined from the survey questions with the risk aversion parameter from the experiment. For the latter, we use the midpoint of the 
subjects' range of risk aversion parameter values. For the job gamble series, the correlation coefficient is positive but insignificant $(\rho=0.11, p=0.12, \mathrm{n}=198)$. For the investment gamble series the correlation is larger, positive and significant $(\rho=0.16, p=0.08, \mathrm{n}=113)$. Restricting the sample to respondents who answered both series of survey questions in a consistent manner increases the size of both correlation coefficients, and greatly increases the statistical significance of the correlation between the experimental measure and the inheritance-based classification. For the job gamble series, the correlation increases to $0.16(p=0.12, \mathrm{n}=97)$ and for the inheritance gamble series the correlation increases to $0.22(p=0.03, \mathrm{n}=97)$. This is more evidence that the risk preference measure based on the inheritance gambles has a stronger relationship with the risk aversion parameter from the lottery choice experiment, and moreover, that restricting the sample to "consistently consistent" subjects strengthens the association between the measures.

In terms of the coefficients on other variables in the model, we find some evidence that female subjects were more risk averse in the lottery choice experiment. All of the coefficients on the female indicator are positive in Tables 5 and 6, and half are significant. In a recent review of the gender and risk aversion literature, Eckel and Grossman (forthcoming) reported that most field experiments and context-free laboratory experiments also find significant associations between female gender and risk aversion. ${ }^{10}$ The coefficients on the other controls in our models

\footnotetext{
${ }^{10}$ The coefficient on female is significant in some of our models of lottery choice behavior even after controlling for risk preference with the survey-based measures. This is consistent with previously reported findings. For example, Agnew et al. (2008) found that females were significantly more likely to choose a safe financial asset (an annuity) than a more risky (marketbased) asset, even after controlling for the level of risk aversion using a lottery choice experiment. Combined, these results suggest that survey-based and experimental measures of risk aversion do not fully capture gender differences in risky decision making. While not the subject of this study, this is a fruitful area for research.
} 
(nonwhite race, academic year, and parental income) were statistically insignificant. ${ }^{11}$ Excluding these indicator variables from the models had no effect on the pattern of results for the risk classification coefficients.

\section{Discussion and Conclusions}

Survey-based measures of risk preference have been shown to have significant effects in many models of decision-making under uncertainty including investment and asset accumulation, insurance demand, smoking and alcohol use, and marriage and fertility. Recent experimental studies have shown that real-world behaviors also can be explained by risk aversion parameters defined from lottery choices with real monetary payoffs. In this study we examine the degree to which these methods produce similar estimates of risk aversion using a within-subjects design.

Among the majority of subjects in this study, we find that risk preferences are not stable across our elicitation methods. For subjects who responded to the job gamble questions in a consistent manner, risk classification defined from the survey questions had no significant association with risk preference defined from the lottery choice task. This finding is consistent with evidence of risk preference instability reported in prior studies (e.g., Berg et al. 2005; Isaac and James 2000; Kruse and Thompson 2003).

Closer inspection of our data reveals two interesting findings. First, risk aversion classifications based on survey responses vary with context. We find that a much higher fraction

11 In a specification test, we used indicator variables for subject age in place of the dummies for academic year. Indicator variables were adopted because there was little variation in the ages of the subjects; more than $96 \%$ of our subjects were between the ages of 18 and 22 . Indicator variables for 20 years, 21 years, 22 years and 23 years or more had insignificant coefficients, and the use of these controls had no effect on the coefficients of the response category indicators. Because missing data on age reduced our sample sizes by a few observations, we chose to report results with the academic year indicators in the tables. 
of respondents gave inconsistent responses to the survey questions about inheritances. It is possible that subjects thought more carefully about career changes than about windfall gains, even though both were hypothetical. It may also be that boredom or fatigue set in during the second set of questions. Focusing on subjects whose responses were consistent in each series, we find that responses to the inheritance gamble questions suggest a higher degree of risk tolerance. This is reflected in Table 3; further the mean of a 6-category scale of risk aversion is 3.72 among the 198 subjects with valid responses to the job series, and 3.17 among the 113 with valid responses to the inheritance series. This difference remains when the sample is restricted to respondents who supplied consistent responses to both series ( 3.78 compared to $3.19, \mathrm{n}=97$ ). The higher degree of risk tolerance in the inheritance series may be due to differences in how subjects made decisions about windfall gains such as inherited wealth, compared to nondiscretionary income from earnings.

A second intriguing finding from our study is that for some subjects, there is evidence of risk preference stability across the two elicitation mechanisms. When we consider only those subjects who made consistent choices in both series of hypothetical questions, we observe a stronger association between cardinal measures of risk aversion defined from both sets of gamble questions and risk preference defined from the lottery choice experiment. In the case of the inheritance-based risk classification, the sample restriction produces a significant positive association with risk preference defined in the experiment. This is especially worth noting given the differences in the stakes of the two elicitation methods, and the hypothetical nature of the survey responses. This finding stands in contrast to the evidence reported in Berg et al. (2005), in which none of the risk preference parameters had a significant coefficient when included in 
regressions of other parameters.

Since sample restrictions increase the estimated coefficients on both survey-based measures, we view this as evidence that unobserved traits of the "consistently consistent" subjects enhance the stability of risk preference estimates. We posit that those traits may be comprehension or effort. A similar observation was made by James (2007) in a series of experiments using the BDM procedure. Because these experiments included a treatment with a dominant strategy prediction, subjects who understood the experiment could be identified. Subjects who followed the dominant strategy in the initial round of the experiment exhibited significantly more stable preferences across multiple rounds than those who did not. ${ }^{12}$

Combined, these results suggest the need for future research to identify finer measures of subject effort and ability to be included in tests of risk preference stability. In light of the recent focus on field experiments and the use of non-traditional subject pools, another possible area for research is exploring whether subject pool composition is related to preference stability. Until more is known in this area, our results suggest that policymakers should remain cautious in extrapolating measures of risk preference across elicitation instruments and across broader populations.

${ }^{12}$ A somewhat related finding is reported by Dave et al. (2007), who found that excluding subjects with lower math ability yielded similar estimates of predictive accuracy across two experimental elicitation methods. 


\section{Acknowledgments}

This research was supported by the Schroeder Center for Healthcare Policy at the Thomas

Jefferson Program in Public Policy at the College of William \& Mary. The authors are grateful for valuable research assistance from Nathan Koch, Matthew Altamura, and Jennifer Kessler. 


\section{References}

Agnew, Julie R., Lisa R. Anderson, Jeffrey R. Gerlach and Lisa R. Szykman. (2008). "Who Chooses Annuities? An Experimental Investigation of the Role of Gender, Framing and Defaults," American Economic Review Papers and Proceedings 98(2), 418-422.

Andersen, Steffen, Glenn W. Harrison, Morten I. Lau and E. Elisabet Rutström. (2008). "Lost in State Space: Are Preferences Stable?” International Economic Review 49(3), 1091-1112.

Anderson, Lisa R. and Jennifer M. Mellor. (forthcoming). "Predicting Health Behaviors with an Experimental Measure of Risk Preference," Journal of Health Economics.

Barsky, Robert B, Miles Kimball, F. Thomas Juster and Matthew Shapiro. (1997). "Preference Parameters and Behavioral Heterogeneity: An Experimental Approach in the Health and Retirement Study," Quarterly Journal of Economics 112 (2), 537-79.

Becker, Gordon M., Morris H. DeGroot and Jacob Marschak, (1964). "Measuring Utility by a Single-Response Sequential Method,” Behavioral Science 9, 226-232.

Berg, Joyce, John Dickhaut and Kevin McCabe. (2005). "Risk Preference Instability Across Institutions: a Dilemma," Proceedings of the National Academy of Sciences 201(11), 4209-4214.

Brown, Sarah and Karl Taylor. (2007). "Education, Risk Preference, and Wages," Manuscript, Department of Economics, University of Sheffield.

Camerer, Colin F. and Robin M. Hogarth. (1999). "The Effects of Financial Incentives in Experiments: A Review and Capital-Labor-Production Framework," Journal of Risk and Uncertainty 19 (1-3), 7-42.

Charles, Kerwin Kofi and Charles Hurst. (2003). "The Correlation of Wealth Across Generations," Journal of Political Economy 111, 1155-1182.

Cox, James C., Bruce Roberson and Vernon L. Smith. (1982). "Theory and Behavior of SingleObject Auctions" in V.L. Smith, (ed), Research in Experimental Economics, Volume 2. Greenwich, Comm: JAI Press, Inc.

Dave, Chetan, Catherine Eckel, Cathleen Johnson and Christian Rojas. (2007). "Eliciting Risk Preferences: When is Simple Better?" working paper.

Dave, Dhaval and Henry Saffer. (2007). "Risk Tolerance and Alcohol Demand Among Adults and Older Adults," National Bureau of Economic Research Working Paper Number 13482. 
Deck, Cary, Jungmin Lee, Javier Reyes and Chris Rosen. (2008). "Measuring Risk Attitudes Controlling for Personality Traits," working paper, June.

Dohmen, Thomas, Armin Falk, David Huffman, Uwe Sunde, Jurgen Schupp and Gert G. Wagner. (2005). "Individual Risk Attitudes: New Evidence from a Large, Representative, Experimentally-Validated Survey," IZA Discussion Paper No. 1730.

Eckel, Catherine and Philip Grossman. (2002) "Sex Differences and Statistical Stereotyping in Attitudes toward Financial Risk," Evolution and Human Behavior 23(4), 281-295.

Eckel, Catherine and Philip Grossman. (forthcoming). "Men, Women and Risk Aversion: Experimental Evidence," in Charles Plott and Vernon Smith, (eds.), Handbook of Experimental Economics Results, Volume 1. City: New York, North-Holland Publishing.

Elston, Julie Ann, Glenn W. Harrison and E. Elisabet Rutström.(2005). "Characterizing the Entrepreneur Using Field Experiments," Working Paper, Max Planck Institute of Economics.

Harrison, Glenn W., John A. List and Charles Towe. (2007). "Naturally Occurring Preferences and Exogenous Laboratory Experiments: A Case Study of Risk Aversion," Econometrica 75 (2), 433-458.

Hey, John D., Andrea Morone and Ulrich Schmidt. (2007). "Noise and Bias in Eliciting Preferences," Kiel Working Paper Number 1386.

Holt, Charles A. and Susan K. Laury. (2002). "Risk Aversion and Incentive Effects," The American Economic Review 92(5),1644-1655.

Isaac, R. Mark and Duncan James. (2000). “Just Who Are You Calling Risk Averse?” Journal of Risk and Uncertainty 20 (2), 177-187.

James, Duncan. (2007). "Stability of Risk Preference Parameter Estimate Within the BeckerDeGroot-Marschak Procedure," Experimental Economics 10, 123-141.

Kan, Kamhon. (2003). "Residential Mobility and Job Changes Under Uncertainty," Journal of Urban Economics 54, 566-586.

Kimball, Miles S., Claudia R. Sahm and Matthew D. Shapiro. (forthcoming). "Imputing Risk Tolerance From Survey Responses," Journal of the American Statistical Association.

Kruse, Jamie Brown and Mark A. Thompson. (2003). "Valuing Low Probability Risk: Survey and Experimental Evidence," Journal of Economic Behavior and Organization 50, 495505. 
Lahiri, Kajal and Jae G. Song. (2000). "The Effect of Smoking on Health Using a Sequential Self-Selection Model," Health Economics 9, 491-511.

Lusardi, Annamaria. (1998). "On the Importance of the Precautionary Saving Motive," American Economic Review 88 (2), 449-453.

Lusk, Jayson L and Keith H. Coble. (2005). "Risk Perceptions, Risk Preference, and Acceptance of Risky Food," American Journal of Agricultural Economics 87(2), 393-405.

Picone, Gabriel, Frank Sloan and Donald Taylor, Jr. (2004). "Effects of Risk and Time Preference and Expected Longevity on Demand for Medical Tests," The Journal of Risk and Uncertainty 28 (1), 39-53.

Rosen, Harvey S. and Stephen Wu. (2004). "Portfolio Choice And Health Status," Journal of Financial Economics 72(3), 457-484.

Sahm, Claudia. (2007). "How Much Does Risk Tolerance Change?" Finance and Economics Discussion Series, Division of Research \& Statistics and Monetary Affairs, Federal Reserve Board.

Schmidt, Lucie. (2008). "Risk Preferences and the Timing of Marriage and Childbearing." Demography 45(2), 439-460.

Sloan, Frank A. and Edward C. Norton. (1997). "Adverse Selection, Bequests, Crowding Out, and Private Demand for Insurance: Evidence from the Market for Long Term Care Insurance," Journal of Risk and Uncertainty 15(3), 210-219.

Spivey, Christy. (2007). "Desperation or Desire? The Role of Risk Aversion in Marriage," Working Paper, Department of Economics, Southern Illinois University Edwardsville.

von Gaudecker, Hans-Martin, Arthur van Soest and Erik Wengström. (2008). "Selection and Mode Effects in Risk Preference Elicitation Experiments," IZA Discussion Paper Number 3321.

Weber, Elke U., Ann-Renee Blais, and Nancy E. Betz. (2002). "A Domain-specific Risk-attitude Scale: Measuring Risk Perceptions and Risk Behaviors." Journal of Behavioral Decision Making, 15: 263-290. 
Table 1. Lottery Choices in the Experiment

\begin{tabular}{|c|c|c|c|}
\hline Decision & Option A & Option B & $E(A)-E(B)$ \\
\hline 1 & $\begin{array}{l}\text { Receive } \$ 6.00 \text { if die throw is } 1 ; \\
\text { Receive } \$ 4.80 \text { if die throw is } 2-10\end{array}$ & $\begin{array}{l}\text { Receive } \$ 11.55 \text { if die throw is } 1 ; \\
\text { Receive } \$ 0.30 \text { if die throw is } 2-10\end{array}$ & 3.50 \\
\hline 2 & $\begin{array}{l}\text { Receive } \$ 6.00 \text { if die throw is } 1-2 ; \\
\text { Receive } \$ 4.80 \text { if die throw is } 3-10\end{array}$ & $\begin{array}{l}\text { Receive } \$ 11.55 \text { if die throw is } 1-2 \\
\text { Receive } \$ 0.30 \text { if die throw is } 3-10\end{array}$ & 2.49 \\
\hline 3 & $\begin{array}{l}\text { Receive } \$ 6.00 \text { if die throw is } 1-3 \\
\text { Receive } \$ 4.80 \text { if die throw is } 4-10\end{array}$ & $\begin{array}{l}\text { Receive } \$ 11.55 \text { if die throw is } 1-3 \text {; } \\
\text { Receive } \$ 0.30 \text { if die throw is } 4-10\end{array}$ & 1.49 \\
\hline 4 & $\begin{array}{l}\text { Receive } \$ 6.00 \text { if die throw is } 1-4 \text {; } \\
\text { Receive } \$ 4.80 \text { if die throw is } 5-10\end{array}$ & $\begin{array}{l}\text { Receive } \$ 11.55 \text { if die throw is } 1-4 \\
\text { Receive } \$ 0.30 \text { if die throw is } 5-10\end{array}$ & 0.48 \\
\hline 5 & $\begin{array}{l}\text { Receive } \$ 6.00 \text { if die throw is } 1-5 ; \\
\text { Receive } \$ 4.80 \text { if die throw is } 6-10\end{array}$ & $\begin{array}{l}\text { Receive } \$ 11.55 \text { if die throw is } 1-5 \text {; } \\
\text { Receive } \$ 0.30 \text { if die throw is } 6-10\end{array}$ & -0.53 \\
\hline 6 & $\begin{array}{l}\text { Receive } \$ 6.00 \text { if die throw is } 1-6 \text {; } \\
\text { Receive } \$ 4.80 \text { if die throw is } 7-10\end{array}$ & $\begin{array}{l}\text { Receive } \$ 11.55 \text { if die throw is } 1-6 \text {; } \\
\text { Receive } \$ 0.30 \text { if die throw is } 7-10\end{array}$ & -1.53 \\
\hline 7 & $\begin{array}{l}\text { Receive } \$ 6.00 \text { if die throw is } 1-7 \\
\text { Receive } \$ 4.80 \text { if die throw is } 8-10\end{array}$ & $\begin{array}{l}\text { Receive } \$ 11.55 \text { if die throw is } 1-7 \text {; } \\
\text { Receive } \$ 0.30 \text { if die throw is } 8-10\end{array}$ & -2.54 \\
\hline 8 & $\begin{array}{l}\text { Receive } \$ 6.00 \text { if die throw is } 1-8 \text {; } \\
\text { Receive } \$ 4.80 \text { if die throw is } 9-10\end{array}$ & $\begin{array}{l}\text { Receive } \$ 11.55 \text { if die throw is } 1-8 \text {; } \\
\text { Receive } \$ 0.30 \text { if die throw is } 9-10\end{array}$ & -3.54 \\
\hline 9 & $\begin{array}{l}\text { Receive } \$ 6.00 \text { if die throw is } 1-9 \\
\text { Receive } \$ 4.80 \text { if die throw is } 10\end{array}$ & $\begin{array}{l}\text { Receive } \$ 11.55 \text { if die throw is } 1-9 \text {; } \\
\text { Receive } \$ 0.30 \text { if die throw is } 10\end{array}$ & -4.55 \\
\hline 10 & Receive $\$ 6.00$ if die throw is $1-10$ & Receive $\$ 11.55$ if die throw is $1-10$ & -5.55 \\
\hline
\end{tabular}


Table 2. Lottery Choices and Risk Aversion $(n=236)$

\begin{tabular}{ccc}
\hline \hline Number of Safe Choices & Proportion of Subjects & Range of Relative Risk Aversion \\
\hline $0-1$ & 0.000 & $\mathrm{r}<-0.95$ \\
2 & 0.000 & $-0.95<\mathrm{r}<-0.49$ \\
3 & 0.047 & $-0.49<\mathrm{r}<-0.15$ \\
4 & 0.208 & $-0.15<\mathrm{r}<0.15$ \\
5 & 0.195 & $0.15<\mathrm{r}<0.41$ \\
6 & 0.275 & $0.41<\mathrm{r}<0.68$ \\
7 & 0.170 & $0.68<\mathrm{r}<0.97$ \\
8 & 0.072 & $0.97<\mathrm{r}<1.37$ \\
$9-10$ & 0.034 & $1.37<\mathrm{r}$ \\
\hline
\end{tabular}


Table 3. Subject Risk Aversion Based on Responses to Hypothetical Gamble Questions (n=236)

\begin{tabular}{|c|c|c|}
\hline Category & $\begin{array}{c}\text { Job } \\
\text { Series }\end{array}$ & $\begin{array}{c}\text { Inheritance } \\
\text { Series }\end{array}$ \\
\hline $\begin{array}{l}\text { Risk Aversion Category } 1 \text { (least risk averse): } \\
\text { Accepted risky job/investment when loss was 33\%, 50\% and } 75 \% \\
\text { of income/inheritance. }\end{array}$ & $\begin{array}{c}7 \\
(3 \%)\end{array}$ & $\begin{array}{c}8 \\
(3.4 \%)\end{array}$ \\
\hline $\begin{array}{l}\text { Risk Aversion Category } 2 \text { : } \\
\text { Accepted risky job/investment when loss was } 33 \% \text { and } 50 \% \text { of } \\
\text { income/inheritance; Rejected risky job/investment when loss was } \\
75 \% \text { of income/inheritance. }\end{array}$ & $\begin{array}{c}19 \\
(8.1 \%)\end{array}$ & $\begin{array}{c}37 \\
(15.7 \%)\end{array}$ \\
\hline $\begin{array}{l}\text { Risk Aversion Category } 3 \text { : } \\
\text { Accepted risky job/investment when loss was } 33 \% \text { of } \\
\text { income/inheritance; Rejected risky job/investment when loss was } \\
50 \% \text { and } 75 \% \text { of income/inheritance. }\end{array}$ & $\begin{array}{c}47 \\
(19.9 \%)\end{array}$ & $\begin{array}{c}25 \\
(10.6 \%)\end{array}$ \\
\hline $\begin{array}{l}\text { Risk Aversion Category } 4 \text { : } \\
\text { Rejected risky job/investment when loss was } 33 \% \text { of } \\
\text { income/inheritance; Accepted risky job/investment when loss was } \\
20 \% \text { and } 10 \% \text { of income/inheritance. }\end{array}$ & $\begin{array}{c}81 \\
(34.3 \%)\end{array}$ & $\begin{array}{c}26 \\
(11 \%)\end{array}$ \\
\hline $\begin{array}{l}\text { Risk Aversion Category 5: } \\
\text { Rejected risky job/investment when loss was } 33 \% \text { and } 20 \% \\
\text { income/inheritance; Accepted risky job/investment when loss was } \\
10 \% \text { of income/inheritance. }\end{array}$ & $\begin{array}{c}38 \\
(16.1 \%)\end{array}$ & $\begin{array}{c}5 \\
(2.2 \%)\end{array}$ \\
\hline $\begin{array}{l}\text { Risk Aversion Category } 6 \text { (most risk averse): } \\
\text { Rejected risky job/investment when loss was } 33 \%, 20 \% \text {, and 10\% } \\
\text { of income/inheritance. }\end{array}$ & $\begin{array}{c}6 \\
(2.5 \%)\end{array}$ & $\begin{array}{c}12 \\
(5.1 \%)\end{array}$ \\
\hline Responded "don't know" to any of the five questions & $\begin{array}{c}21 \\
(8.9 \%)\end{array}$ & $\begin{array}{c}18 \\
(7.6 \%)\end{array}$ \\
\hline $\begin{array}{l}\text { Responded to series of questions in an inconsistent manner: Either } \\
\text { accepted the risky job/investment after having rejected when } \\
\text { downside risk was smaller, or rejected the risky job/investment after } \\
\text { having accepted when downside risk was larger. }\end{array}$ & $\begin{array}{c}17 \\
(7.2 \%)\end{array}$ & $\begin{array}{c}105 \\
(44.5 \%)\end{array}$ \\
\hline
\end{tabular}


Table 4. Comparison of Response Categories using Different Series of Gamble Questions

\begin{tabular}{|c|c|c|c|c|c|c|c|}
\hline \multirow{2}{*}{$\begin{array}{l}\text { Risk Aversion } \\
\text { Category Based } \\
\text { on Job Gambles }\end{array}$} & \multicolumn{6}{|c|}{ Risk Aversion Category Based on Inheritance Gambles } & \multirow[b]{2}{*}{$\mathrm{n}$} \\
\hline & $\begin{array}{l}1 \text { (least } \\
\text { risk } \\
\text { averse) }\end{array}$ & 2 & 3 & 4 & 5 & $\begin{array}{l}6 \text { (most } \\
\text { risk } \\
\text { averse) }\end{array}$ & \\
\hline $\begin{array}{l}1 \text { (least risk } \\
\text { averse) }\end{array}$ & $\begin{array}{c}1 \\
25 \% \\
13 \%\end{array}$ & $\begin{array}{c}1 \\
25 \% \\
3 \%\end{array}$ & $\begin{array}{c}0 \\
0 \% \\
0 \%\end{array}$ & $\begin{array}{c}1 \\
25 \% \\
4 \%\end{array}$ & $\begin{array}{c}1 \\
25 \% \\
20 \%\end{array}$ & $\begin{array}{c}0 \\
0 \% \\
0 \%\end{array}$ & 4 \\
\hline 2 & $\begin{array}{c}2 \\
17 \% \\
25 \%\end{array}$ & $\begin{array}{c}6 \\
50 \% \\
21 \%\end{array}$ & $\begin{array}{c}2 \\
17 \% \\
9 \%\end{array}$ & $\begin{array}{c}1 \\
8 \% \\
4 \%\end{array}$ & $\begin{array}{c}0 \\
0 \% \\
0 \%\end{array}$ & $\begin{array}{c}1 \\
8 \% \\
10 \%\end{array}$ & 12 \\
\hline 3 & $\begin{array}{c}1 \\
6 \% \\
13 \%\end{array}$ & $\begin{array}{c}4 \\
24 \% \\
14 \%\end{array}$ & $\begin{array}{c}6 \\
35 \% \\
27 \%\end{array}$ & $\begin{array}{c}4 \\
24 \% \\
17 \%\end{array}$ & $\begin{array}{c}0 \\
0 \% \\
0 \%\end{array}$ & $\begin{array}{c}2 \\
12 \% \\
20 \%\end{array}$ & 17 \\
\hline 4 & $\begin{array}{c}3 \\
8 \% \\
38 \%\end{array}$ & $\begin{array}{c}9 \\
24 \% \\
31 \%\end{array}$ & $\begin{array}{c}8 \\
22 \% \\
36 \%\end{array}$ & $\begin{array}{c}14 \\
38 \% \\
61 \%\end{array}$ & $\begin{array}{c}1 \\
3 \% \\
20 \%\end{array}$ & $\begin{array}{c}2 \\
5 \% \\
20 \%\end{array}$ & 37 \\
\hline 5 & $\begin{array}{c}1 \\
5 \% \\
13 \%\end{array}$ & $\begin{array}{c}8 \\
36 \% \\
28 \%\end{array}$ & $\begin{array}{c}6 \\
27 \% \\
27 \%\end{array}$ & $\begin{array}{c}2 \\
9 \% \\
9 \%\end{array}$ & $\begin{array}{c}3 \\
14 \% \\
60 \%\end{array}$ & $\begin{array}{c}2 \\
9 \% \\
20 \%\end{array}$ & 22 \\
\hline $\begin{array}{l}6 \text { (most risk } \\
\text { averse) }\end{array}$ & $\begin{array}{c}0 \\
0 \% \\
0 \%\end{array}$ & $\begin{array}{c}1 \\
20 \% \\
3 \%\end{array}$ & $\begin{array}{c}0 \\
0 \% \\
0 \%\end{array}$ & $\begin{array}{c}1 \\
20 \% \\
4 \%\end{array}$ & $\begin{array}{c}0 \\
0 \% \\
0 \%\end{array}$ & $\begin{array}{c}3 \\
60 \% \\
30 \%\end{array}$ & 5 \\
\hline $\mathrm{n}$ & 8 & 29 & 22 & 23 & 5 & 10 & 97 \\
\hline
\end{tabular}

Notes: Except for those in the bottom row and far right column, each cell contains the frequency, followed by the row percentage and column percentage. 
Table 5. Interval Regressions of Relative Risk Aversion on Gamble Response Categories

\begin{tabular}{|c|c|c|c|c|}
\hline \multirow[t]{3}{*}{ Explanatory Variable } & \multicolumn{2}{|c|}{$\begin{array}{l}\text { Risk Aversion Defined from Job } \\
\text { Gamble Responses }\end{array}$} & \multicolumn{2}{|c|}{$\begin{array}{l}\text { Risk Aversion Defined from } \\
\text { Inheritance Gamble Responses }\end{array}$} \\
\hline & $\begin{array}{l}\text { Excludes } \\
\text { “don't know” } \\
\text { responses } \\
\end{array}$ & $\begin{array}{l}\text { Includes } \\
\text { “don't know” } \\
\text { responses } \\
\end{array}$ & $\begin{array}{l}\text { Excludes } \\
\text { “don't know" } \\
\text { responses } \\
\end{array}$ & $\begin{array}{l}\text { Includes } \\
\text { “don't know" } \\
\text { responses }\end{array}$ \\
\hline & (1) & (2) & (3) & (4) \\
\hline Risk Aversion Category 3 & $\begin{array}{l}-0.133 \\
(0.110)\end{array}$ & $\begin{array}{l}-0.137 \\
(0.107)\end{array}$ & $\begin{array}{l}0.159 \\
(0.108)\end{array}$ & $\begin{array}{c}0.165 \\
(0.104)\end{array}$ \\
\hline Risk Aversion Category 4 & $\begin{array}{l}-0.065 \\
(0.103)\end{array}$ & $\begin{array}{l}-0.073 \\
(0.100)\end{array}$ & $\begin{array}{c}0.088 \\
(0.109)\end{array}$ & $\begin{array}{c}0.090 \\
(0.105)\end{array}$ \\
\hline Risk Aversion Category 5 & $\begin{array}{c}0.091 \\
(0.115)\end{array}$ & $\begin{array}{c}0.082 \\
(0.112)\end{array}$ & $\begin{array}{l}0.595^{* * *} \\
(0.207)\end{array}$ & $\begin{array}{l}0.616^{* * *} \\
(0.200)\end{array}$ \\
\hline Risk Aversion Category 6 & $\begin{array}{c}0.025 \\
(0.199)\end{array}$ & $\begin{array}{c}0.027 \\
(0.194)\end{array}$ & $\begin{array}{c}0.144 \\
(0.146)\end{array}$ & $\begin{array}{c}0.155 \\
(0.121)\end{array}$ \\
\hline "Do not know" response & & $\begin{array}{l}-0.075 \\
(0.127)\end{array}$ & & $\begin{array}{c}0.103 \\
(0.121)\end{array}$ \\
\hline Female & $\begin{array}{l}0.115^{*} \\
(0.064)\end{array}$ & $\begin{array}{l}0.130^{* *} \\
(0.059)\end{array}$ & $\begin{array}{c}0.133 \\
(0.083)\end{array}$ & $\begin{array}{l}0.142^{*} \\
(0.074)\end{array}$ \\
\hline Number of observations & 198 & 219 & 113 & 131 \\
\hline $\begin{array}{l}\chi^{2} \text { statistic for test of joint } \\
\text { significance of risk aversion } \\
\text { category coefficients } \\
\text { (p-value) }\end{array}$ & $\begin{array}{c}6.1 \\
(0.19)\end{array}$ & $\begin{array}{c}6.37 \\
(0.17)\end{array}$ & $\begin{array}{l}9.33 \\
(0.05)\end{array}$ & $\begin{array}{l}10.79 \\
(0.03)\end{array}$ \\
\hline
\end{tabular}

Notes: Coefficients from interval regressions models, with standard errors in parenthesis. Statistical significance indicated by ** (5\% level) and * (10\% level). All models also include controls for subject race, and indicator variables for academic year and parental income categories. 
Table 6. Interval Regressions of Relative Risk Aversion from Lottery Choice Task on Cardinal Risk Aversion Parameters Imputed from Gamble Responses

\begin{tabular}{lcccc}
\hline \hline Explanatory variable & $(1)$ & $(2)$ & $(3)$ & $(4)$ \\
\hline Risk aversion defined from job series & 0.029 & & 0.043 & \\
& $(0.029)$ & & $(0.038)$ & \\
& & 0.036 & & $0.050^{*}$ \\
Risk aversion defined from inheritance series & & $(0.026)$ & & $(0.029)$ \\
& & & & 97 \\
Number of observations & 198 & 113 & 97 & 97 \\
\hline
\end{tabular}

Notes: Coefficients from interval regressions models, with standard errors in parenthesis. Statistical significance indicated by * (10\% level). All models also include controls for subject sex, race, academic year, and parental income level. 


\section{Appendix 1. Lottery Choice Experiment Instructions}

You will be making choices between two lotteries, such as those represented as "Option A" and "Option B" below. The money prizes are determined by the computer equivalent of throwing a ten-sided die. Each outcome, 1, 2, 3, 4, 5, 6, 7, 8, 9, 10, is equally likely. Thus if you choose Option A, you will have a 1 in 10 chance of earning $\$ 6.00$ and a 9 in 10 chance of earning $\$ 4.80$. Similarly, Option B offers a 1 in 10 chance of earning $\$ 11.55$ and a 9 in 10 chance of earning $\$ 0.30$.

Decision

$1 \mathrm{st}$
Option A

$\$ 6.00$ if the die is 1 $\$ 4.80$ if the die is $2-10$
Option B

$\$ 11.55$ if the die is 1

$\$ 0.30$ if the die is $2-10$
Your Choice

A: or B:

- $\quad$ Each row of the decision table contains a pair of choices between Option A and Option B.

- $\quad$ You make your choice by clicking on the "A" or "B" buttons on the right. Only one option in each row can be selected, and you may change your decision as you wish.

- Note: Try clicking on one of the circles and then change by clicking on the other one.

\section{Decision}

$1 \mathrm{st}$

\section{Option A}

$\$ 6.00$ if the die is 1 $\$ 4.80$ if the die is $2-10$

2nd
$\$ 6.00$ if the die is $1-2$

$\$ 4.80$ if the die is $3-10$

\section{Option B}

$\$ 11.55$ if the die is 1

$\$ 0.30$ if the die is $2-10$

$\$ 11.55$ if the die is $1-2$

$\$ 0.30$ if the die is $3-10$
Your Choice

A: or B:

A: or B:

Even though you will make ten decisions, only one of these will end up being used. The selection of the one to be used depends on the "throw of the die" that is the determined by the computer's random number generator. No decision is any more likely to be used than any other, and you will not know in advance which one will be selected, so please think about each one carefully. This random selection of a decision fixes the row (i.e. the Decision) that will be used. For example, suppose that you make all ten decisions and the throw of the die is 9 , then your choice, A or B, for decision 9 below would be used and the other decisions would not be used.

$\begin{array}{cccc}\text { Decision } & \text { Option A } & \text { Option B } & \text { Your Choice } \\ . & \$ 6.00 \text { if the die is } 1-9 & \$ 11.55 \text { if the die is } 1-9 & \\ . & \$ 4.80 \text { if the die is } 10 & \$ 0.30 \text { if the die is } 10 & \text { A: } \mathbf{B}:\end{array}$


After the random die throw fixes the Decision row that will be used, we need to obtain a second random number that determines the earnings for the Option you chose for that row. In Decision 9 below, for example, a throw of $1,2,3,4,5,6,7,8$, or 9 will result in the higher payoff for the option you chose, and a throw of 10 will result in the lower payoff.

$\begin{array}{cccc}\text { Decision } & \begin{array}{c}\text { Option A } \\ \text { 9th }\end{array} & \begin{array}{c}\text { Option B } \\ \$ 6.00 \text { if the die is } 1-9\end{array} & \text { Your Choice } \\ & \$ 4.80 \text { if the die is } 10 & \$ 0.30 \text { if the die is } 10 & \text { A: or B: } \\ \text { 10th } & \$ 6.00 \text { if the die is } 1-10 & \$ 11.55 \text { if the die is } 1-10 & \text { A: or B: }\end{array}$

For decision 10, the random die throw will not be needed, since the choice is between amounts of money that are fixed: $\$ 6.00$ for Option A and $\$ 11.55$ for Option B.

- $\quad$ Making Ten Decisions: After you finish these instructions, you will see a table with 10 decisions in 10 separate rows, and you choose by clicking on the buttons on the right, option A or option B, for each of the 10 rows. You may make these choices in any order and change them as much as you wish until you press the Submit button at the bottom.

- The Relevant Decision: One of the rows is then selected at random, and the Option (A or B) that you chose in that row will be used to determine your earnings. Note: Please think about each decision carefully, since each row is equally likely to end up being the one that is used to determine payoffs.

- $\quad$ Determining the Payoff for Each Round: After one of the decisions has been randomly selected, the computer will generate another random number that corresponds to the throw of a ten sided die. The number is equally likely to be $1,2,3, \ldots 10$. This random number determines your earnings for the Option (A or B) that you previously selected for the decision being used.

- $\quad$ Determining the Final Payoff: There will be 2 rounds, and therefore, you will encounter 2 choice menus, each with 10 rows. You will find out your earnings for each of these menus as one of the rows is randomly selected. Please Note: We will use all rounds to determine your final earnings. Your total earnings will equal the sum of your earnings for the 2 menus.

\section{Instructions Summary $($ ID $=)$}

To summarize, you will indicate an option, A or B, for each of the rows by clicking on the "radio buttons" on the right side of the table.

Then a random number fixes which row of the table (i.e. which decision) is relevant for your earnings.

In that row, your decision fixed the choice for that row, Option A or Option B, and a final random number will determine the money payoff for the decision you made. 


\section{Appendix 2. Hypothetical Gamble Questions}

\section{A. Job Change Series}

Suppose that you are the only income earner in the family. Your doctor recommends that you move because of allergies, and you have to choose between two possible jobs. The first would guarantee you an annual income for life that is equal to your parents' current total family income. The second is possibly better paying, but the income is also less certain. There is a 50-50 chance the second job would double your total lifetime income and a 50-50 chance that it would cut it by a third. Which job would you take -- the first job or the second job?

1. First job

2. Second job

3. Do not know

Suppose the chances were 50-50 that the second job would double your lifetime income, and 5050 that it would cut it in half. Would you take the first job or the second job?

1. First job

2. Second job

3. Do not know

Suppose the chances were 50-50 that the second job would double your lifetime income and 5050 that it would cut it by seventy-five percent. Would you take the first job or the second job?

1. First job

2. Second job

3. Do not know

Suppose the chances were 50-50 that the second job would double your lifetime income and 5050 that it would cut it by twenty percent. Would you take the first job or the second job?

1. First job

2. Second job

3. Don't know

Suppose the chances were 50-50 that the second job would double your lifetime income and 5050 that it would cut it by 10 percent. Would you take the first job or the second job?

1. First job

2. Second job

3. Do not know 


\section{B. Inheritance Series}

Suppose that a distant relative left you a share in a private business worth one million dollars. You are immediately faced with a choice -- whether to cash out now and take the one million dollars, or to wait until the company goes public in one month, which would give you a 50-50 chance of doubling your money to two million dollars and a 50-50 chance of losing one-third of it, leaving you 667 thousand dollars. Would you cash out immediately or wait until after the company goes public?

1. Cash out

2. Wait

3. Do not know

Suppose that waiting a month, until after the company goes public, would result in a 50-50 chance that the money would be doubled to two million dollars and a 50-50 chance that it would be reduced by half, to 500 thousand dollars. Would you cash out immediately and take the one million dollars, or wait until the company goes public?

1. Cash out

2. Wait

3. Do not know

Suppose the chances were 50-50 that waiting would double your money to two million dollars and 50-50 that it would reduce it by seventy-five percent, to 250 thousand dollars. Would you cash out immediately and take the one million dollars, or wait until after the company goes public?

1. Cash out

2. Wait

3. Do not know

Suppose that waiting a month, until after the company goes public, would result in a 50-50 chance that the money would be doubled to two million dollars and a 50-50 chance that it would be reduced by twenty percent, to 800 thousand dollars. Would you cash out immediately and take the one million dollars, or wait until after the company goes public?

1. Cash out

2. Wait

3. Do not know

Suppose the chances were 50-50 that waiting would double your money to two million dollars and 50-50 that it would reduce it by ten percent, to 900 thousand dollars. Would you cash out immediately and take the one million dollars, or wait until after the company goes public?

1. Cash out

2. Wait

3. Do not know 